\title{
On Reform of Large Data Environments Computer Course---in Case Study Data Structure Course
}

\author{
Jie Zhang ${ }^{1, a}$, Qiang Huang ${ }^{1, b^{*}}$ and Jing Zhang ${ }^{1, c}$ \\ ${ }^{1}$ College of Information and Engineering, Sichuan Agricultural University, 625014, China \\ a185511591@126.com, b19623556@qq.com, 617985835@qq.com
}

*The corresponding author

Keywords: Big data; Micro course; Autonomous learning course; Online interactive

\begin{abstract}
Big data is more and more profound influence on the society as a whole, has gradually penetrated into all aspects of education. The transformation of teaching thinking under the era of big data, flip classroom, MOOC and micro courses are profoundly changing the traditional education mode. Positive research on the curriculum reform, in the case of data structure course, discusses the computer class exploration of curriculum reform in sichuan agricultural university, the implementation of curriculum resources based on online interactive network platform, teaching, practice and the new teachers' teaching view change.
\end{abstract}

\section{First, the Era of Big Data Transformation of Teaching Thinking}

Big data is changing the world, especially important of which is changing people's way of thinking. Based on cloud computing, Internet and database technology, social network technology mature application, such as for courses, flip the classroom, micro... Education resources are more abundant, making the quality education is not necessarily depend on the class, and bring the real reason for these changes, are the big data [1]. If large data got involved in a world characterized by data, data analysis and prediction of time, then, turn the classroom, MOOC, micro course is the era of big data in the field of education caused a prelude to a revolution, it makes the informationization teaching is facing a new environment, the resource view, teaching view, teachers' development and so on all new changes will occur.

Under the Big Data Thinking Change the Education Concept. One prominent feature of the era of big data, characterized by sharp growth, digital data thinking and significant changes in the way to work. Today, the Internet of things, cloud computing, big data technology for the rapid development of education research has brought new possibilities, by big data technology to monitor all the data in the process of access to education. Education will be after economics, is no longer a concept and experience of social science and conscience, the education of the era of large data, will become a real empirical science. [2]

Learning and Transfer of the Space. In the era of big data, people will break the traditional classroom teaching mode of learning. Using the Fragment learning at any time and any place can autonomic learning. Students in the growth process must cultivate self-learning ability in order to improve awareness of initiative and innovation. Amount of learning resources in network has changed in the way people acquire knowledge of the extent and manner.

\section{Second, the Teaching Reform of Computer Courses in Our School under the Background of Big Data Era}

Currently Teaching Computer Courses Common Problem. An important link of the specialized courses for computer is programming. Interconnectedness between courses is relatively large, to student's programming ability and practice ability of the demand is higher. Some students because the early stages of the course have not learned, in the subsequent stage of learning can't adapt to the requirement of application development, resulting in a decline in learning enthusiasm, and affect the subsequent course of study. Although in modern education, people advocate using a variety of 
teaching methods, but the teaching method has the advantages of concentrated in spreading knowledge, short time and high efficiency, and can make the students get a lot of knowledge and skills in a short time, and for the further development of intelligence and cultivate the ability to lay a good foundation, so the teaching method in classroom teaching still has obvious advantages. But teaching method cannot realize difference teaching, direct practice and feedback in time, sometimes even affect the student's positive initiative and ignore the existence of individual difference, and teaching method must be combined with other teaching methods to better impart knowledge in the classroom.

The Big Data Applications in the Computer Education and Teaching in Our School. Big data era, colleges and universities information center recorded about the behavior of the students left the resource sharing platform way such as unstructured data, and the data processing center's mission is to analyze the data, digging, in some way is presented to students, let students understand themselves in the activities of all kinds of resources subsystem and the activity type and condition of a certain period of learning, realize truly personalized learning [2].

In recent years, our school's own development and bought a variety of learning and testing platform, such as sichuan agricultural university courses learning platform, online interactive network teaching platform, computer simulation experiments, the computer algorithm simulation platform, sichuan agricultural university machine test platform, etc. Students browse multimedia learning materials on the open platform, the usual practice and the system can record each student's learning progress, pay attention to study the dynamic, such as individual information, make learning system can help students improve the knowledge structure and promote the students' own specialty training and exploring the depth of interest.

\section{Third, Based on the Big Data into Online Interactive Network Teaching Platform Teaching Computer Courses}

The following to the "data structure" of teaching this course as an example illustrates the condition of the computer courses teaching in our school. "Data structure" is the core of computer professional courses, both has the rich theoretical system and strong practicality, have the effect of flow in the main courses. But the course is more abstract, and there are a lot more difficult to understand. In the traditional way of teaching tends to obscure the course, so that students lose interest in learning, cannot reach good teaching purposes. More class time less and course content, in the limited classroom teaching of high quality to finish the teaching goal must change the teaching method, and large data online interactive teaching to the teaching reform.

With Knowledge so as to Realize the Teaching Content of Online Learning. In the traditional teaching mode, a good portion of students to obtain knowledge from the teachers' classroom teaching, they lack the motivation and initiative, is more of a passive way. Traditional education to pursue the overall efficiency and curriculum assessment methods single. However, students each person in the process of learning is difference. According to the mastery of teaching idea, students to understand the problem, the time it takes is a variable, through to do not understand the knowledge point of learning can be master repeatedly. This theory emphasizes the differences of each person in the learning process, and narrow difference, but does not affect the top students learning process.

Big data era on study characteristics are as fragmented learning. This is based on Internet technology, according to the knowledge points as the unit for access to information and knowledge. In the course of teaching, teachers advance course content into appropriate online learning small modules, according to knowledge use screen recording software Camtasia recording into about 20 minutes of Micro-teaching video, placed on the course learning platform for students to repeatedly watch and learn. The greatest benefit of this is that, for the basic knowledge, teachers in the classroom do not need to explain repeatedly encountered the individual class cannot understand the point of knowledge; students can preview or choose to re-learn according to their own situation. Knowledge and learning some point you can see the video entirely by way of self-study to complete, teachers in teaching should play a guiding role. In addition, we also built algorithm simulation 
platform that provides students interactively visualize a large number of algorithms, the students in the theoretical study of operating conditions can be performed simultaneously with the actual operation of the image understanding algorithms.

To Strengthen the Students' Learning Interaction, Improve the Teaching Feedback. On Teaching platform, in addition to students outside of online learning, the platform can also be put on the knowledge of each student's learning progress, learning repeatedly state curriculum recorded during exercise, the teachers can clearly know what issues according to these records, what I do not know where students encounter in learning. Facilitate teachers discover the problems in the process of teaching, dynamic learning, assist teachers to further improve the teaching quality.

Curriculum Experiment Shift. "Data Structure" experimental part of course is very important. First of all, we provide a significant amount of experimental material in the course teaching platform, convenient student verification type and comprehensive experiment. Second "data structure" sometimes because of the complexity of the algorithm in the experimental course, teachers explain in advance of time is likely to account for a long time and seriously influence to the process of students' practice, it is also possible that the teacher explained to complete, but the students forget the content or details. So in the experiment course will also explain in detail before the experiment and essentials in the form of micro-programs available to students, students are required to watch before class, teachers are emphatically analyzed in the process of test interpretation and guidance. Besides, in the experiment of the interpretation use of spider mite management software, by teachers' demonstration, students demonstration and establish the discussion groups, facilitate real-time learning between teachers and students and among students communicate, strengthen the interactive classroom. And the teachers found problems in a timely.

The Transformation of Curriculum Evaluation System. Change content and teaching methods, must also change its assessment methods. Examination is the baton of student learning, in order to make the students don't just put energy into the final exam, the first to reform the examination method and grades composition ratio. More at ordinary times the inspection and experiment result. The usual result and experiment result proportion increased to $60 \%$. In the final examination test system based on our self-developed machine for assessment of basic knowledge, accounted for $40 \%$. Usual performance appraisal online assessment and comprehensive assessment by the usual video learning. Online assessment through online interactive network teaching platform, After a big knowledge to enable students to complete the study by the independent test platform to test the knowledge points, test questions using the way of random question, some students are not satisfied with the result of the test can continue to learn after the test again, each person has three chances to repeatedly test study, urged students to learn more effectively, this part accounted for $20 \%$. The remaining $40 \%$ for the experimental results, through on-line measurement system, and the completion and student project programming is evaluated. Comparison chart as follows.

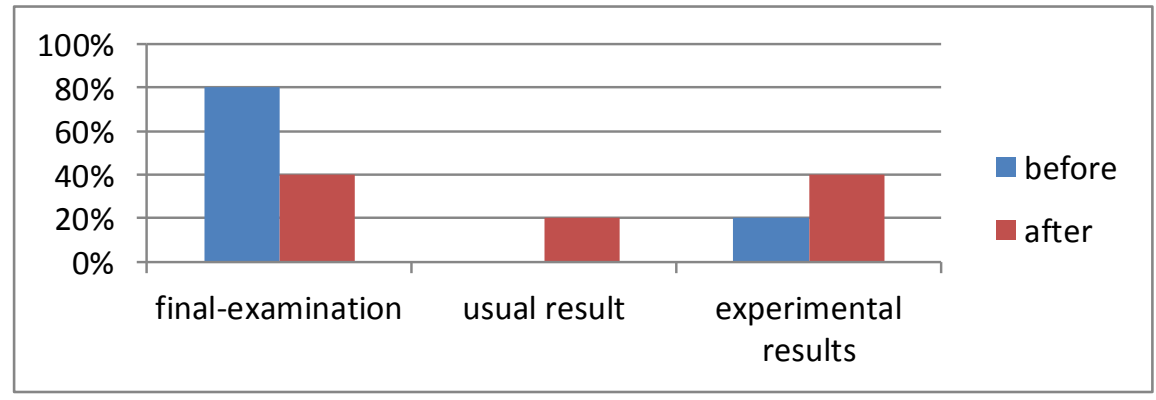

Figure 1. The Transformation of Curriculum Evaluation

Through Data Analysis Improve the Teaching. Teachers can use online interactive network teaching platform, real-time grasp student's learning process and learning effect, to better strengthen the supervision and management, according to different student's reality given more reasonable Suggestions, comments and grades. Show records of panoramic way under the big data, when everything can be "quantitative", teachers' teaching and students learning process can complete are 
continually preserved. Teachers' teaching and students learning process can be a complete record, show the data. This way of tracking the activities between teachers and students can better promote teachers' professional development and the growth of the students education accurately. Each student's education can be established on the basis of analysis of the data in the past behavior, as long as the user leave a mark on the Internet or other media, its behavior characteristics, mindset, hobbies, will take in everything in a glance, to analyze it. In this sense, the future of education will be accurate individualized education.

\section{Summary}

Through the reform of the teaching method and teaching content, students' interest in computer course of practical application and enthusiasm got obvious improvement. Part of the acceptance of weak students in class, in particular, can through online learning before and after class, to improve the understanding of theoretical knowledge and experimental content. Based on data mining and statistics the targeted individuality student tutoring, mastery of course difficulty and explain, to strengthen the interaction with students. Teachers are developers and organizers of the curriculum resources, student questions explore partner and helper. In this mode can form a continuous state of students, one is through the online interactive network platform to solve the problems of the students "know", and the teachers more important guiding role in it. The second is the improvement of theoretical knowledge and practical ability, strengthen the feedback between teachers and students. Flip class and micro course that the traditional resources as the core resources construction in class for students to learning resources development as the core resources construction transformation, the traditional teachers' teaching as the core of the teaching methods for students' autonomous learning, teachers and students together to depth development as the core of the teaching way transformation. Three is to guide the students' autonomous learning, cultivate the online learning habits under the network environment, can take advantage of today's huge network resources for independent learning other knowledge system.

\section{References}

[1] Shijia Zhou, round big data thinking: in this paper, characteristics and significance, (2014)

[2] Zhong Wei, Education is a revolution occurred quietly, Shanghai, (2014)

[3] Xinyi Shen, Wen Hu, Daniel Hickey Online learning engagement and learning strategies to explore and effectiveness analysis, (2015)

[4] Bo Dai, Shijie Zhou, Wenyu Chen, Data Structure The curriculum reform to explore, (2013)

[5] Wenxin Liang, Age of Big Data: The classroom teaching will have real change, (2013)

[6] Peng $\mathrm{Xu}$, Big data perspective change study__ Through education and learning data mining analysis to promote the teaching and learning Report interpretation and enlightenment, (2013)

[7] Hongjian Li, The era of big data computer professional experiment teaching reform research, (2013)

[8] Wenwen Li, Xianyu Han, The exploration of computer professional education era of big data, (2014)

[9] Dan Ju, Liya Zhang, Computer curriculum reform and thinking, (2016)

[10]Ming He, Weiwei Chen, Xiliang Chen, The university computer foundation course reform method based on computational thinking (2014) 